\title{
Botulinum Toxin A, Effect on Tensile Strength of Skin Wounds; Animal Study
}

\author{
Carlos A. Gonzalez-Alvarado', Juan Garzon-Muvdi', Roxanna Perez-Garmendia1, \\ Victoria Ramirez ${ }^{2}$, Luz Graciela Cervantes ${ }^{3}$, Adriana Rodriguez-Gomez ${ }^{4}$, \\ Rodrigo Davila-Diaz ${ }^{1}$, Cuahutemoc Marquez-Espriella ${ }^{1}$
}

${ }^{1}$ Plastic and Reconstructive Surgery Division, Hospital Central Sur de alta Especialidad de Petroleos Mexicanos, Mexico City, Mexico ${ }^{2}$ Experimental Surgery Department, Instituto Nacional de Ciencias Medicas y Nutrición Salvador Zubiran, Mexico City, Mexico ${ }^{3}$ Pharmacology Department Instituto Nacional de Cardiologia Ignacio Chavez, Mexico City, Mexico

${ }^{4}$ Pathology Department, Hospital Angeles del Pedregal, Mexico City, Mexico

Email: garzonmuvdi@gmail.com

How to cite this paper: Gonzalez-Alvarado, C.A., Garzon-Muvdi, J., Perez-Garmendia, R., Ramirez, V., Cervantes, L.G., RodriguezGomez, A., Davila-Diaz, R. and MarquezEspriella, C. (2020) Botulinum Toxin A, Effect on Tensile Strength of Skin Wounds; Animal Study. Journal of Biosciences and Medicines, 8, 17-24.

https://doi.org/10.4236/jbm.2020.82002

Received: December 2, 2019

Accepted: January 19, 2020

Published: January 22, 2020

Copyright $\odot 2020$ by author(s) and Scientific Research Publishing Inc. This work is licensed under the Creative Commons Attribution International License (CC BY 4.0).

http://creativecommons.org/licenses/by/4.0/

\begin{abstract}
Wound healing and cicatrization is a process that involves several phases. The main goal of a surgeon and specially the plastic surgeon is to achieve the best cosmetic results and avoid complications. Several tools are available to achieve the best result. One of the tools recently studied is the use of Botulinum toxin. The use of Botulinum toxin has showed to be a useful aid by improving macroscopic cosmetic changes, as histopathologic ones. The increase of the tensile strength is also one of the positive changes that come with the use of botulinum toxin.
\end{abstract}

\section{Keywords}

Botulinum Toxin, Wound, Tensile Strength

\section{Introduction}

Most of skin wounds heal without complications, such as: infections, wound dehiscence, and delay of scar formation. These complications, continue to be a public health issue by increasing morbidity and mortality rates as well as health costs [1].

The wound healing process, starts immediately after the injury and the result of it, is the formation of scar tissue. This is why it's very important to evaluate the resulting scar and the quality of it.

Wound closure can be achieved by different methods, such as, surgical sutures, surgical staples and surgical adhesives. It is important to achieve this primary closure without tension, to ensure an adequate scar formation [2]. 
Cicatrization, is achieved by a complex process formed by a series of events meant to recover the tissue tension. The skin is considered to be the biggest organ in the economy, representing $16 \%$ of the total body weight. The skin has a wide variety of functions, such as protection (UV light, chemical agents, temperature and against microorganisms), thermoregulation, metabolic function, amongst others. It also has the ability to heal and regenerate which is key to maintain the functions listed above [3] [4].

Usually cicatrization takes place without complication, but in some cases abnormal scar formation may take place, including hypertrophic scar formation and keloid scar formation. Both of them are enlarged, raised scars that may generate a negative psychological (facial scars) and physiological impact (affecting range of motion).

There are risk factors promoting pathological scar formation, such as: high body mass index, diabetes, and others, that may be controlled by the physician which are: wound tension, surgical technique, infection prevention and tobacco use, etc. [5] [6].

\section{Botulinum Toxin}

The botulinum toxin (TBA) is an exotoxin produced by the bacterium Clostridium Botulinum, a spore forming, gram positive bacteria, that acts by inducing a chemo-denervation at the neuromuscular union, at the presynaptic neuron level, generating an irreversible blockade, preventing the liberation of acetylcholine, resulting in striated muscle denervation, that lasts from 2 to 6 months after it's administration, with the resulting muscular fiber atrophy and the clinical flaccid paralysis [7] [8].

Eight serologically distinct types of botulinum toxin exist, botulinum toxin type A (BOTOX ${ }^{\circledR}$; Allergan) was the first commercially available type in the United States [7] [8] [9].

It has been published that Botulinum Toxin A increases the release of Vascular Endothelial Growth Factor (VEGF), P substance, Calcitonin gene-related peptide (CGRP), which stimulate angiogenesis [10]. Substance P induces an acute pro-inflamatory state, which promotes the proliferative phase of cicatrization and modulates macrophages, promoting cicatrization [11].

The use of Botulinum Toxin A (TBA), has been proposed to improve the resulting scar after a wound by cell proliferation regulation, and growth factors expressed by fibroblasts [12] [13]. But its effect has never been tested in the tensile strength in wound healing.

Over 50 million surgeries take place in the US, this without considering traumatic wounds (approximately 50 million), which generates over 250 million of productive days loss. This numbers are without taking in consideration, traumatic wounds estimated to be over 50 million per year [14].

\section{Materials and Methods}

All experiments involving animals were conducted in accordance with the Guide 
for the Care and Use of Laboratory Animals (National Academy Press, Washington, DC, 1996) and were approved by the Institutional Animal Care and Use Committee of Hospital Central Sur de Alta Especialidad de Petroleos Mexicanos,. 20 wistar male rats (270 - $315 \mathrm{~g}$ ) were divided into two groups, one control group and the other group treated with TBA (Figure 1 and Figure 2). All experiments were conducted at the Instituto Nacional de Cardiologia Ignacio Chavez.

\section{Surgery}

Previously anesthetized by using a combination of $20 \mathrm{mg} / \mathrm{kg}$ of $10 \%$ Ketamine, and $2 \mathrm{mg} / \mathrm{kg} 2 \%$ Xylacine. Locally $0.5 \mathrm{ml}$ of lidocaine was administered subcutaneous in the incision zone. Afterwards a $3 \times 3 \mathrm{~cm}$ zone in the dorsum was shaved and then disinfected using $10 \%$ betadine solution.

A linear $2 \mathrm{~cm}$ total skin thickness incision was performed; physiological solution was injected in 4 cardinal points while the TBA group received $5 \mathrm{U} / \mathrm{kg}$ of

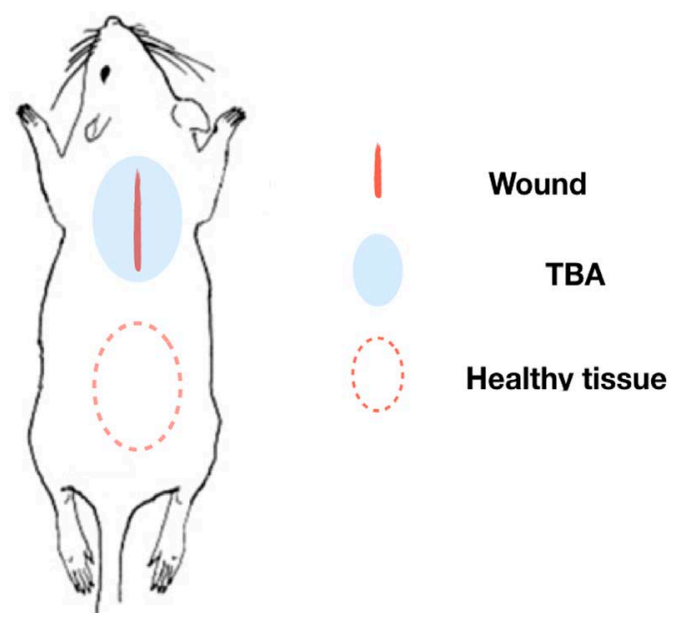

Figure 1. Graphic representation of animals treated with TBA.

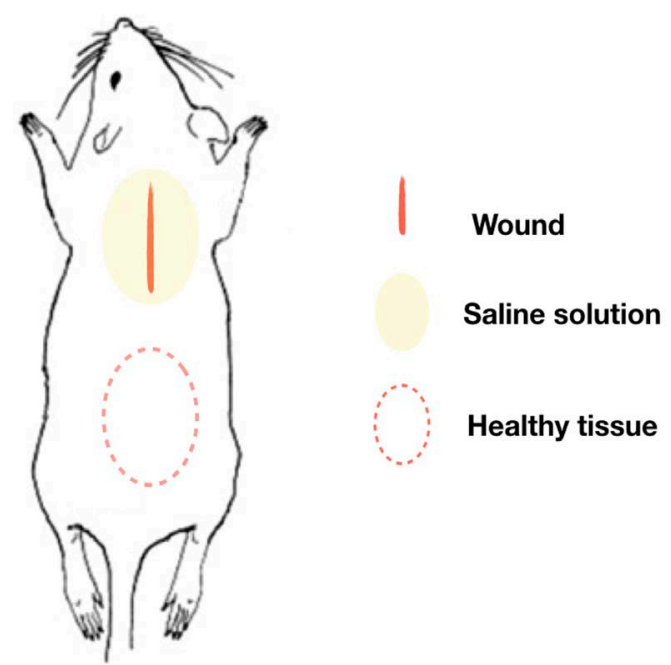

Figure 2. Graphic representation of control group. 
Botulinum ToxinA around the wound (4 quadrants) (Figure 3 and Figure 4).

Primary closure was performed using 3 individual 4-0 sutures (monofilament non absorbable sutures). Immediately after the procedure intraperitoneal ketorolac was administered and pain control continued for the subsequent 5 days using Tramadol and Metamizol that was placed in the drinking water.

The animals were placed in metabolic cages at $23^{\circ} \mathrm{C}$ with a $12: 12$ hour light-dark cycle and were allowed free access to water and food. Sutures were removed after 5 days.

There are no conflicts of interests, TBA and all the supplies used were paid by the investigators.

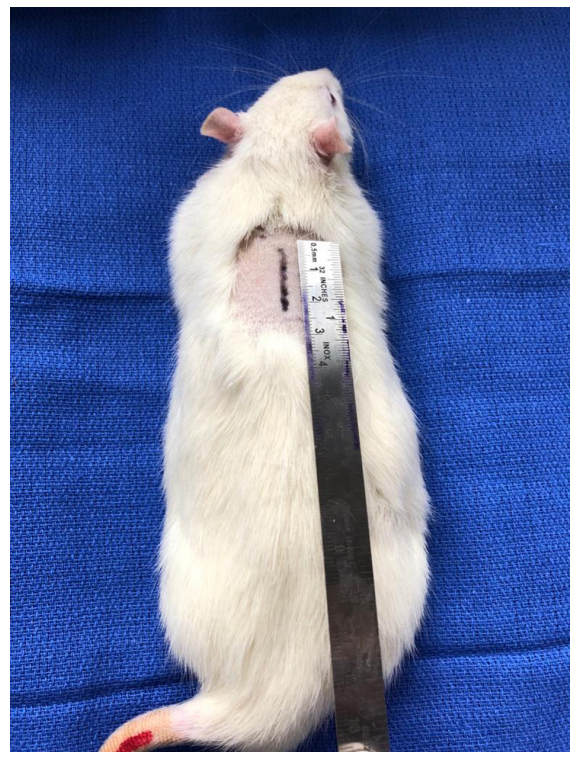

Figure 3. A linear $2 \mathrm{~cm}$ total skin thickness incision.

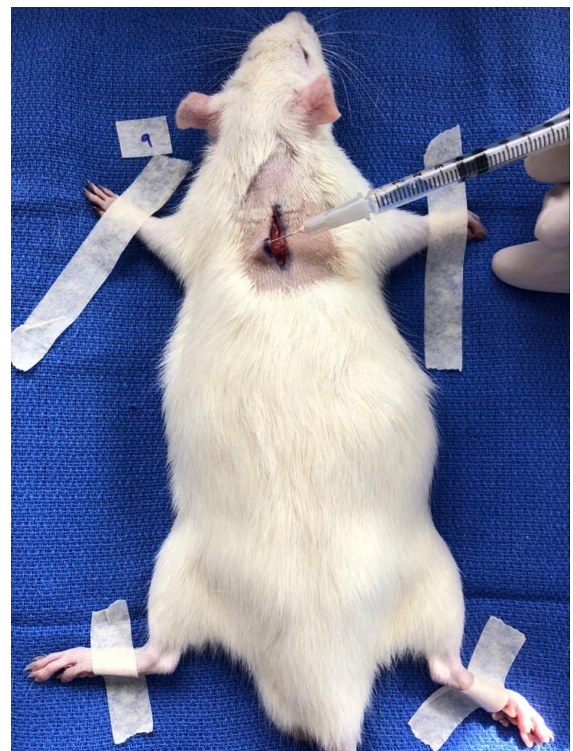

Figure 4. TBA injection administration. 


\section{Samples}

Full thickness biopsies were taken including scar tissue and $3 \mathrm{~cm}$ of surrounding normal tissue, immediately after, the animals were euthanized by administrating a anesthetic overdose. Necessary tensile strength to achieve scar rupture through the suture line was measured using a dynamometer (Davis-Geck ${ }^{\circledast}$ ) (Figure 5). Conventional hematoxylin, eosin and masson trichrome staining was done then were submitted to a descriptive evaluation by the Pathology lab, using an optic microscope $(40 \times$ and $10 \times)$.

\section{Results}

Microscopic appearance showed a subjective difference between both groups, animals treated with Botulinum toxin showed a better cosmetic appearance compared, against, the control group (Figure 6).

Tensile strength compared between both groups showed a significative difference ( $P$ 0.00128) showing an increase in the strength needed to separate the scar in the group treated with TBA, when compared to the control group. In average the force needed in the TBA group was 23.83 newtons; meanwhile the control group needed a strength of 10.25 newtons (Chart 1 ).

The histological analysis studied showed a dense stroma in the TBA group and a lax stroma in the control group (Figure 7). The control group showed more fibroblasts (Figure 7). There was no difference in angiogenesis among both groups.
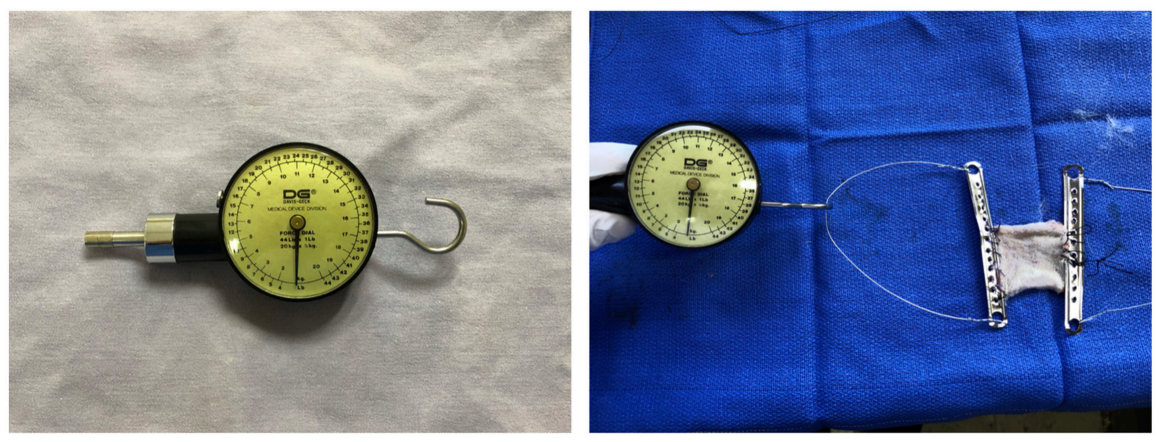

Figure 5. Mechanism used to measure tensile strength.
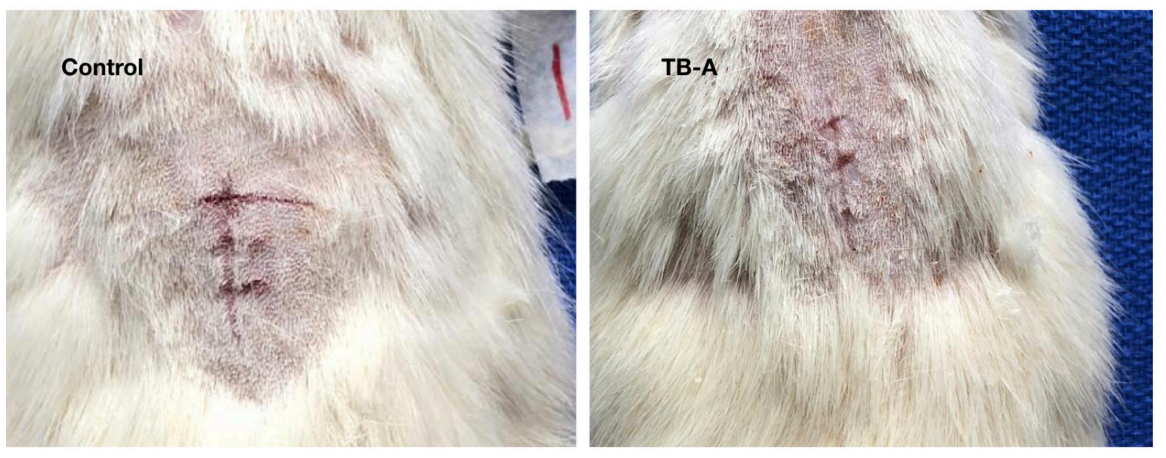

Figure 6. Macroscopic evaluation sample showing better cosmoses in the TBA group. 

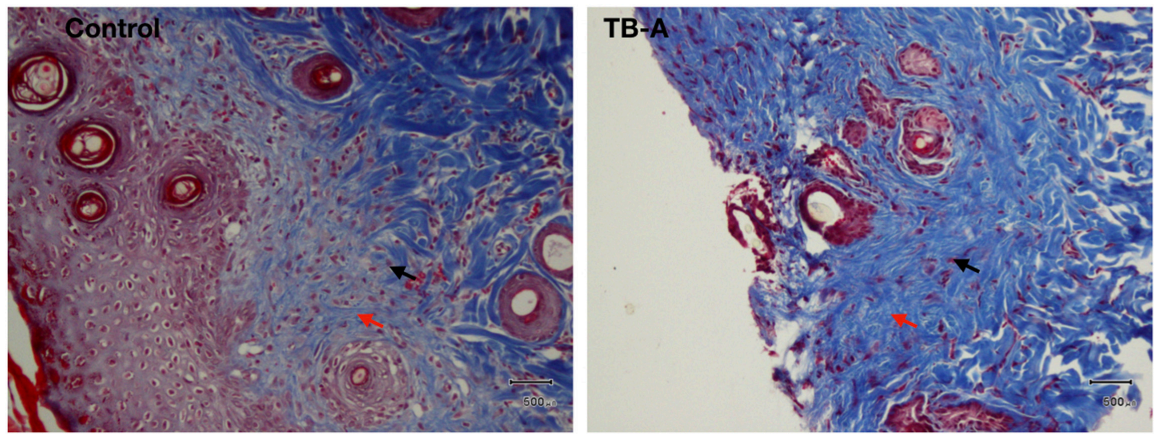

Figure 7. Histological comparison between both groups showing a dense stroma in the TBA group, and a greater number of fibroblasts in the control group when compared. Black arrow points to fibroblasts and red arrow showing stroma.

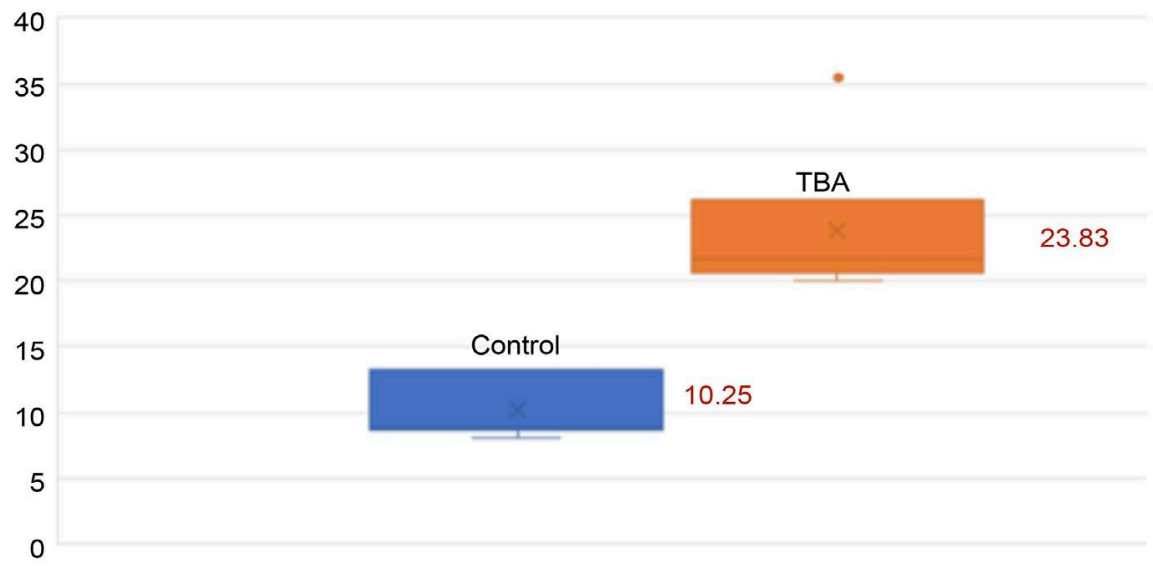

Chart 1. Tensile strength comparison, showing the increase of strength in the TBA group, measured in newtons.

\section{Discussion}

Botulinum Toxin A has been used usually for medical and aesthetic purposes, during the last years its use has been tested in wounds, to prevent and manage pathological scar formation, but the accurate mechanism of action hasn't been described [15].

One of the variables that determines the aesthetic result of the scar is the tension on the wound borders, this may generate an unfavorable scar in a direct way (mechanical) or in a indirect way Chemical). By administrating Botulinum toxin $\mathrm{A}$, tension, perpendicular to the wound borders is diminished by causing temporary muscle paralysis around the lesion. Inmovilization represents one of the basic principles in the scar formation process. Several different tools have been tested to minimice the tension related to muscular movement. Gassner and cols published for the first time the use of Botulinum Toxin A to improve wound border tension [16].

This study tries to evaluate in an objective way the force necessary to separate the wound line when Botulinum toxin $\mathrm{A}$ is used compared to those cases where it is not administered, resulting in a significative difference between both groups 23.83 vs 10.25 newtons respectively. 
Botulinum Toxin A applied in the wound improves the cosmetic result and the tensile strength, not only by diminishing mechanical forces induced by muscular contraction, with may lead to new treatments against chronic or difficult wound management.

The Histological analysis showed more storm and less fibroblasts compared with the control group, which may lead to a better control of collagen fiber production and to a better cicatrization regulation.

\section{Conclusion}

One of the principal problems, that faces a surgeon when creating a surgical wound or when treating a traumatic wound is the evolution of the scar. The use of Botulinum toxin improves the cosmetic appearance and improves the tensile strength; histologically there is a clear difference in the stoma and the fibroblast numbers.

\section{Conflicts of Interest}

The authors declare no conflicts of interest regarding the publication of this paper.

\section{References}

[1] Kirkland, K.B., Briggs, J.P., Trivette, S.L., Wilkinson, W.E. and Sexton, D.J. (1999) The Impact of Surgical-Site Infections in the 1990s: Attributable Mortality, Excess Length of Hospitalization, and Extra Costs. Infection Control \& Hospital Epidemiology, 20, 725-730. https://doi.org/10.1086/501572

[2] Thorne, C.H. (2013) Grabb and Smith's Plastic Surgery. 7th Edition, Lippincott Williams \& Wilkins, Philadelphia, PA.

[3] Jones, A.P., Janis, J.E. and Barnard, A.R. (2014) Essentials of Plastic Surgery. 2nd Edition, CRC Press, Taylor \& Francis Group, Boca Raton, FL.

[4] Childs, D.S. and Murthy, A.S. (2017) Overview of Wound Healing and Management. Surgical Clinics of North America, 97, 189-207.

https://doi.org/10.1016/j.suc.2016.08.013

[5] Kucukkaya, D., Irkoren, S., Ozkan, S. and Sivrioglu, N. (2014) The Effects of Botulinum Toxin A on the Wound and Skin Graft Contraction. The Journal of Craniofacial Surgery, 25, 1908-1911. https://doi.org/10.1097/SCS.0000000000000941

[6] De Maio, M. and Rzany, B. (2007) Botulinum Toxinin Aesthetic Medicine. Springer-Verlag, Berlin, Heidelberg. https://doi.org/10.1007/978-3-540-34095-9

[7] Kasyanju Carrero, L.M., Ma, W.W., Liu, H.F., Yin, X.F. and Zhou, B.R. (2019) Botulinum Toxin Type A for the Treatment and Prevention of Hypertrophic Scars and Keloids: Updated Review. Journal of Cosmetic Dermatology, 18, 10-15. https://doi.org/10.1111/jocd.12828

[8] Carrillo-Córdova, J., Martínez-Wagner, R., Trolle-Silva, A., Bracho-Olvera, H., Carrillo-Córdova, D. and Carrillo-Córdova, L. (2017) La toxina botulínica tipo A se asocia con un incremento en la angiogénesis de las heridas en un modelo murino experimental. Cirugía Plástica, 27, 107-112.

[9] Leal, E.C., Carvalho, E., Tellechea, A., et al. (2015) Substance P Promotes Wound 
Healing in Diabetes by Modulating Inflammation and Macrophage Phenotype. The American Journal of Pathology, 185, 1638-1648.

https://doi.org/10.1016/j.ajpath.2015.02.011

[10] Wilson, A.M. (2006) Use of Botulinum Toxin Type A to Prevent Widening of Facial Scars. Plastic and Reconstructive Surgery, 117, 1758-1766.

https://doi.org/10.1097/01.prs.0000209944.45949.d1

[11] Xiao, Z., Zhang, M., Liu, Y. and Ren, L. (2011) Botulinum Toxin Type a Inhibits Connective Tissue Growth Factor Expression in Fibroblasts Derived from Hypertrophic Scar. Aesthetic Plastic Surgery, 35, 802-807. https://doi.org/10.1007/s00266-011-9690-3

[12] Bloemen, M.C., Ulrich, M.M., Molema, G., van Zuijlen, P.P., Middel-Koop, E. and Niessen, F.B. (2009) Potential Cellular and Molecular Causes of Hypertrophic Scar Formation. Burns, 35, 15-29. https://doi.org/10.1016/j.burns.2008.06.020

[13] Zielins, E.R., Atashroo, D.A., Maan, Z.N., et al. (2014) Wound Healing: An Update. Regenerative Medicine, 9, 817-830. https://doi.org/10.2217/rme.14.54

[14] Shaarawy, E., Hegazy, R.A. and Abdel Hay, R.M. (2015) Intralesional Botulinum Toxin Type A Equally Effective and Better Tolerated than Intralesional Steroid in the Treatment of Keloids: A Randomized Controlled Trial. Journal of Cosmetic Dermatology, 14, 161-166. https://doi.org/10.1111/jocd.12134

[15] Gassner, H.G., Sherris, D.A. and Otley, C.C. (2000) Treatment of Facial Wounds with Botulinum Toxin A Improves Cosmetic Outcome in Primates. Plastic and Reconstructive Surgery, 105, 1948-1953.

https://doi.org/10.1097/00006534-200005000-00005

[16] Courtiss, E.H., Longacre, J.J., DeStefano, G.A., Loredana, B. and Holmstrand, K. (1963) The Placement of Elective Skin Incisions. Plastic and Reconstructive Surgery, 31, 31-44. https://doi.org/10.1097/00006534-196301000-00004 